\title{
DO INTER-SPECIFIC DIFFERENCES IN SEED SIZE DETERMINE NATURAL REGENERATION TRAITS IN PINUS PINEA AND PINUS SYLVESTRIS?
}

\author{
CALAMA, R. ${ }^{1,4 *}$ - MANSO, R. ${ }^{2}$ - BARBEITO, I. ${ }^{2}$ - MAdRIGAL, G. ${ }^{1,4}$ - GARRIGA, E. ${ }^{1}$ - GoRdo, F.J. ${ }^{3}-$ \\ MONTERO, G. ${ }^{1,4}$ - CAÑELLAS, I. ${ }^{1,4}$-PARDOS, M. ${ }^{1,4}$ \\ ${ }^{1}$ CIFOR - INIA. Ctra. de la Coruña, km 7.5. 28040 Madrid, Spain \\ ${ }^{2}$ Laboratoire d'Etude des Ressources Forêt-Bois (LERFoB). INRA. 54280 Champenoux, France \\ ${ }^{3}$ Servicio Territorial de Medio Ambiente: Junta de Castilla y León. C. Duque de la Victoria, 5. \\ 47001 Valladolid, Spain \\ ${ }^{4}$ Instituto Universitario de Gestión Forestal Sostenible. Uva - INIA \\ * Corresponding author: \\ e-mail: rcalama@inia.es; phone: +34-91-3476-868; fax:+34-91-3476-767
}

(Received $8^{\text {th }}$ Oct 2014; accepted $1^{\text {st }}$ Dec 2014)

\begin{abstract}
Inter-specific difference in seed size is one of the main factors influencing regeneration strategies in plant species. The classical trade-off theory postulates that the species with larger seeds produce smaller amounts of offspring that colonize fewer microsites, although a large amount of reserves permits seeds to germinate and survive in a broader range of conditions. Contrarily, the species with smaller seeds are assumed to widely disseminate their seeds, attaining lower rates of seedling establishment and survival. We tested this hypothesis by analysing regeneration traits in Pinus pinea L. (large-seeded species, average seed weight: $700 \mathrm{mg}, \mathrm{SD}: \pm 200 \mathrm{mg}$ ) and Pinus sylvestrais L. (small-seeded species: average seed weight: $13 \mathrm{mg}, \mathrm{SD}: \pm 4.2 \mathrm{mg}$ ). We used data from regeneration trials in inland Spain to analyse five different attributes: 1) seed production and masting habit, 2) seed shadow, 3) annual pattern of emergence and seed success, 4) spatial pattern of seedling emergence, and 5) seedling survival. Our results show that those attributes defining the spatial pattern of regeneration in both species match the assumptions related to their seed size. However, when these species grow under limiting environments, the annual pattern of emergence and seedling survival does not follow the expected trade-off theory.
\end{abstract}

Keywords: trade-off theory, masting habit, seed dispersal, seed shadow, seedling survival

\section{Introduction}

The different reproductive strategies in plant species are defined by a wide array of plant features. Among these specific characteristics, seed size has been defined as the most selective trait, conditioning the spatial and temporal pattern of recruitment of the species (Harper et al., 1970; Moles and Westoby, 2006; Muller-Landau, 2010). Seed size, expressed as weight, may vary between species over a range of ten magnitude orders, between $10^{-6} \mathrm{~g}$ in some orchid species to more than $25000 \mathrm{~g}$ in coconut palm (Harper et al., 1970; Westoby et al., 1992). There are various adaptive hypotheses for seed size differences between species, all based on the theoretical trade-off hypothesis by Smith and Fretwell (1974), which postulates that the mother plant's resources for producing seeds are limited. The allocation of available resources to seeds is partitioned between number and size; thus, the number of seeds borne is determined by the size of the annual assimilated income, the proportion of income allocated to seeds and some specific traits, such as the size of the seed (Harper et al., 1970; Smith and Fretwell, 
1974; Moles and Westoby, 2006). Accordingly, a species with smaller seeds will produce a larger number of propagules, which will reach a greater number of sites, in comparison to a species with larger seeds (Westoby et al., 1992; Muller-Landau, 2010). On the other hand, the greater amount of metabolic reserves in larger seeds results in a wider range of conditions for germination (Aizen and Paterson, 1990; Westoby et al., 1992) as well as greater initial seedling growth and survival (Baker, 1972), especially in stressing environments (Pardos et al., 2005; Muller-Landau, 2010). Furthermore, largeseeded species are expected to show other evolutionary strategies, such as masting habit (the synchronic pattern of annual seed production, Kelly, 1994).

Specific differences in seed size have also been identified as the main characteristic explaining invasiveness of the species (Grotkopp et al., 2002) and reproductive strategy differentiation (Moles and Westoby, 2006) between pioneer r-strategist species and later succession $k$-strategist species (Gross, 1984; Kimmins, 2002). Interspecific differences in seed size have been widely studied in tropical forests (Smythe, 1970; Jackson, 1981; Foster 1986), temperate Quercus forests (Aizen and Woodcock, 1992; Long and Jones, 1996) and several herb or shrub species (Baker, 1972; Gross, 1984), while less attention has been paid to the comparison of regeneration strategies as a response to species' seed size in the genus Pinus, one of the tree genus which displays the greatest between-species variability in seed weight (270-fold order of magnitude, Lanner, 1998).

The main objective of this study is to describe and compare regeneration strategies according to their contrasting seed size in two pine species with a wide distribution in Spain: Pinus pinea L., a Mediterranean sensu-stricto species, and Pinus sylvestris L., a montane Eurosiberian species. $P$. pinea seeds are the largest of the Mediterranean pines, attaining weights over $700 \mathrm{mg}$ (SD $\pm 200 \mathrm{mg}$ ). Seeds can be up to $20 \mathrm{~mm}$ in length and have a short, rudimentary wing. The main agents described for seed dispersal - apart from gravity - are corvids (Cyanopica cyanus Bonaparte), and hoarding rodents (Apodemus sylvaticus L.), though the real effect of dispersers on the regeneration process has not been evaluated so far. At the other end of the spectrum, P. sylvestris seeds are among the smallest of the genus, with an average weight of $13 \mathrm{mg}$ (SD: \pm 4.2 $\mathrm{mg}$ ), maximum length of $5 \mathrm{~mm}$ and a fully developed wing of 12-17 $\mathrm{mm}$ in length (Ruiz de la Torre and Ceballos 1979), being a typical wind-dispersed species. Natural regeneration failure is common in managed $P$. pinea forests (Calama and Montero, 2007), while $P$. sylvestris regenerates satisfactorily, except in mountain timberline (Montero et al., 2008; Barbeito et al., 2011).

Our main hypothesis is that the regeneration strategies observed for $P$. pinea and $P$. sylvestris on their optimal distribution area must reflect the evolutionary advantages in regeneration associated with large-seeded and small-seeded species formalized in the classical trade-off theory by Smith and Fretwell (1974). To evaluate this main hypothesis we have contrasted five secondary hypotheses defining the expected behaviour for large-seeded and small-seeded species -- according to trade-off theory with the observed data from different regeneration trials installed in two representative forests of the species. These secondary hypotheses can be summarised as (1) seed production and masting habit: in large-seeded species number of produced seeds is reduced and the presence of mast year becomes the rule, while small-seeded species produce a sufficient amount of seeds every year (Westoby et al., 1992); (2) seed shadow (spatial pattern of seed dispersal): small-seeded species with wing are widely and uniformly distributed while seed shadow from large-seeded show a clustered 
distribution (Lanner, 1998; Guo et al., 2000) ; (3) annual pattern of seedling emergence and seed success: trade-off theory indicates that the high amount of reserves which a large-seeded species invest in seed production favours germination even under less favourable conditions, so in large-seeded species annual seedling emergence is positively related to previous year seed dispersal (Harper and Obeid, 1967; Jackson, 1981), showing higher rates of seed success (ratio between the emerged seedlings and the seeds dispersed the year before); (4) spatial pattern of seedling emergence: such pattern is expected to mimic that of seed arrival for large-seeded species (Aizen and Paterson, 1990; Moles and Westoby, 2006), while shows larger unevenness in smallseeded ones (Moles and Westoby 2004) since safe sites are less common at scales associated with small seeds (Lusk and Kelly, 2003); and (5) seedling survival: higher survival rates and a broader range of conditions to survive are expected in larger seeded species (Foster, 1986).

\section{Material}

\section{Study sites}

We used data from different regeneration trials installed for both species in public managed forests in the centre of Spain, which are broadly representative of the natural distribution area (Figure 1). P. sylvestris occupies the mid-mountain slopes of the Central Range at an altitude between $1000-1800 \mathrm{~m}$, characterized by a montane humid climate (average annual rainfall $800-1000 \mathrm{~mm}$ ). $P$. pinea grows on the flat sedimentary areas defined by Duero river Basin, located to the north of the Central Range at an altitude of between 700 and $900 \mathrm{~m}$. P. pinea occupies poor sandy soils and grows under a severe, dry continental climate (average annual rainfall $450 \mathrm{~mm}$ and extreme summer and winter temperatures). The studied region is the unique location where the natural distribution areas for both species overlap, even identifying a few relict mixed stands (Robledo-Arnuncio et al., 2005, Figure 1).

\section{Experimental design}

Experimental trials were designed and installed independently for each species to study and model the processes involved in natural regeneration. However, the experimental design is quite consistent for both species, consisting of a set of large plots (ca. $0.5 \mathrm{ha}$ ) installed in mature natural stands. The $P$. pinea trial $(780 \mathrm{~m}$ a.s.1., $41^{\circ} 28^{\prime} 23^{\prime} ' \mathrm{~N}-4^{\circ} 43^{\prime} 27^{\prime}$ ' $\mathrm{W}$ ) included six plots where different natural regeneration fellings were applied. Current stand basal area and stand density ranges from $7-14$ $\mathrm{m}^{2} /$ ha and $37-76$ stems/ha (Table 1). The P. sylvestris trial included three plots: two (plots 1and6) located in the most productive area of the forest $(1400 \mathrm{~m}$ a.s.l., $40^{\circ} 49^{\prime} 01^{\prime}$ ' $\mathrm{N} ; 4^{\circ} 01^{\prime} 30^{\prime}$ ' $\mathrm{O}$ ), in different stages of group shelterwood felling (basal areas 16 and $41 \mathrm{~m}^{2} /$ ha, stand density 168 and 318 stems/ha, respectively), and a third plot (plot 8) located in the timberline region (1800 $\mathrm{m}$ a.s.1., 40 48'38' $\mathrm{N} ; 4^{\circ} 03^{\prime} 33^{\prime}{ }^{\prime} \mathrm{O}$ ) where only selective cuttings (basal area $20 \mathrm{~m}^{2} / \mathrm{ha}$, stand density 320 stems/ha) are applied (Table 1). 


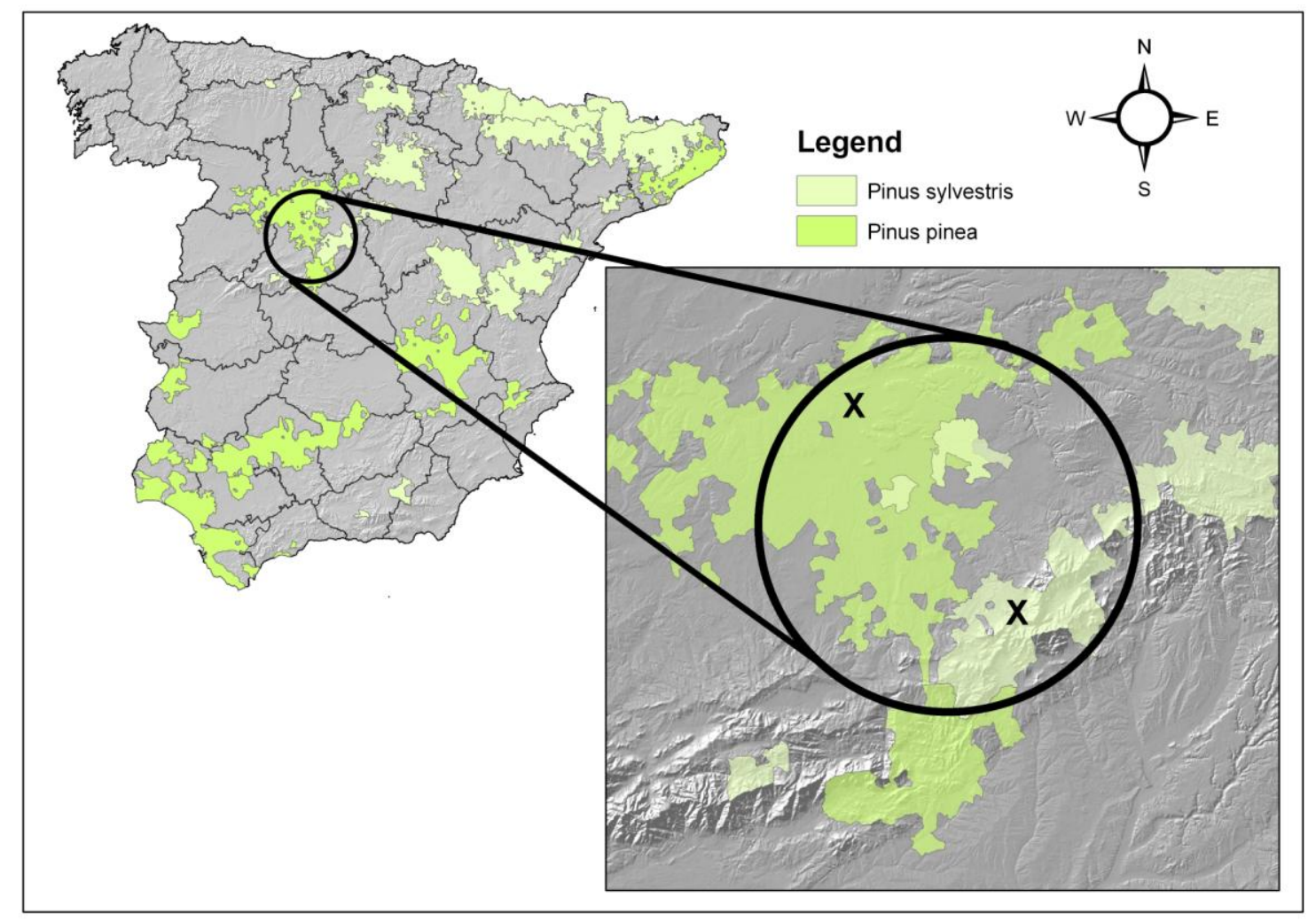

Figure 1. Distribution area for the species in Spain, studied area, and trials location $(X)$

At each plot, a systematic grid of ten ( $P$. sylvestris, $n=30)$ or twenty ( $P$. pinea, $n=120) 9 \mathrm{~m}^{2}$ squared subplots was installed. Subplots were visually surveyed every six months, and new emerged seedlings were counted, numerated, positioned within $1 \mathrm{~m}^{2}$ quadrats and their height was measured. At each subsequent survey, survival and height of the remaining seedlings was also recorded.

In the $P$. pinea trial, fifty-eight seed traps (ten per plot, but two were destroyed during the experiment) were deployed, consisting of a circular bag made of fine mesh textile stapled on three wooden sticks $1 \mathrm{~m}$ above the ground, with a collecting surface of $0.25 \mathrm{~m}^{2}$. In the $P$. sylvestris trial fifteen seed traps (five per plot) were maintained, consisting of a PVC $1 \mathrm{~m}^{2}$ rectangular trap, with micro-holes for drainage in the bottom, and protected with a $4 \mathrm{~cm}^{2}$ mesh to prevent predation. Between May 2005 and February 2010, P. pinea traps were emptied monthly (47 collections, average period between collections 35.2 days). For $P$. sylvestris, winter access difficulties reduced the sampling to a minimum of one collection per season (26 collections between May 2005 and September 2009, average period 58.6 days). Once in the laboratory, seeds from each trap and collection were separated from the litterfall and counted.

Since $P$. pinea plots were located within the same environment, all the analyses for this species were undertaken using the pooled data. In the case of $P$. sylvestris, the most productive area (plots 1 and 6) was considered separately from the timberline site (plot 8 ) for the main part of the analysis. 
Table 1. Main characteristics of the experimental trials in Pinus pinea and Pinus sylvestris

\begin{tabular}{|c|c|c|c|c|}
\hline & & Pinus pinea & $\begin{array}{c}\text { Pinus sylvestris } \\
\text { Plots land6 }\end{array}$ & $\begin{array}{c}\text { Pinus sylvestris } \\
\text { Plot } 8\end{array}$ \\
\hline \multirow{7}{*}{$\begin{array}{l}\text { Regeneration } \\
\text { plots }\end{array}$} & Number of plots & 6 & 2 & 1 \\
\hline & Area of each plot & 0.48 ha & 0.5 ha & 0.5 ha \\
\hline & Basal area (m2/ha) & $7-14$ & $16-40$ & 20 \\
\hline & Stand age & 120 & 120 & 140 \\
\hline & Altitude (m) & 800 & 1400 & 1800 \\
\hline & Silvicultural system & $\begin{array}{c}\text { Seed tree } \\
\text { Shelterwood }\end{array}$ & Shelterwood & Selective cuttings \\
\hline & $\begin{array}{l}\text { Last regeneration } \\
\text { fellings }\end{array}$ & 2003 & 2005 & 2000 \\
\hline \multirow{7}{*}{$\begin{array}{l}\text { Seedling } \\
\text { survey } \\
\text { subplots }\end{array}$} & Number per plot & 20 & 10 & 10 \\
\hline & Type of subplot & Squared $9 \mathrm{~m}^{2}$ & Squared $9-25 \mathrm{~m}^{2}$ & Squared $9 \mathrm{~m}^{2}$ \\
\hline & Subplot Location & Systematic & Systematic & Systematic \\
\hline & $\begin{array}{l}\text { Area sampled per } \\
\text { plot }\end{array}$ & $180 \mathrm{~m}^{2}$ & $90-154 \mathrm{~m}^{2}$ & 90 \\
\hline & Total area sampled & $1080 \mathrm{~m}^{2}$ & $244 \mathrm{~m}^{2}$ & 90 \\
\hline & Survey periodicity & Twice per year & Twice per year & Twice per year \\
\hline & Monitoring years & $2006-2010$ & $2006-2009$ & $2006-2009$ \\
\hline \multirow{6}{*}{ Seed traps } & Number per plot & $10^{*}$ & 5 & 5 \\
\hline & Type of trap & $\begin{array}{c}0.25 \mathrm{~m}^{2} \text { textile } \\
\text { mesh }\end{array}$ & $1 \mathrm{~m}^{2} \mathrm{PVC}$ box & $1 \mathrm{~m}^{2} \mathrm{PVC}$ box \\
\hline & Trap Location & Systematic & Systematic & Systematic \\
\hline & $\begin{array}{l}\text { Area sampled per } \\
\text { plot }\end{array}$ & $2.5 \mathrm{~m}^{2}$ & $5 \mathrm{~m}^{2}$ & $5 \mathrm{~m}^{2}$ \\
\hline & $\begin{array}{l}\text { Collection } \\
\text { periodicity }\end{array}$ & Monthly & Seasonally & Seasonally \\
\hline & Monitoring years & $2005-2009$ & $2005-2008$ & $2005-2008$ \\
\hline
\end{tabular}

* In plot 1, two traps were destroyed during the study, so they were not considered in the analysis

\section{Methods}

\section{Seed production and masting habit}

Seed production was computed for species and sites using the total number of seeds collected per $\mathrm{m}^{2}$, while masting habit was described by the two following statistics:

- Interannual within-trap coefficient of variation $\left(\mathrm{CV}_{\mathrm{i}}\right)$ :

$$
\mathrm{CV}_{\mathrm{i}}=\frac{\sqrt{\sum_{\mathrm{j}=1}^{5}\left[\mathrm{x}_{\mathrm{ij}}-\overline{\mathrm{x}}_{\mathrm{i}}\right]^{2}}}{\overline{\mathrm{x}}_{\mathrm{i}}}
$$

Where xij is the total number of seeds collected in trap i during the jth year of study, $\bar{x}_{i}$ is the average annual value of seeds collected in the trap i. Larger values of CVi indicate larger interannual variability. Given the non-normal nature of $\mathrm{CV}_{\mathrm{i}}$ as well as the unbalanced data (58 traps in $P$. pinea, 15 traps in $P$. sylvestris), between species and between sites differences in $\mathrm{CV}_{\mathrm{i}}$ were evaluated by using a nonparametric KruskalWallis test. 
- Kendall's coefficient of concordance (W):

This coefficient was used to test whether the annual rank in collected seeds between the different traps within the same site and species is independent, or if, contrarily, a pattern of synchrony exists. W ranges between zero (independence) and 1 (complete synchrony) (Legendre, 2005).

\section{Seed shadow}

To contrast the secondary hypothesis of larger uniformity in seed shadow for largeseeded species, we have analysed the spatial pattern of seed dispersal of each species and site by computing:

- Coefficient of variation between traps:

$$
\mathrm{CV}=\frac{\sqrt{\sum_{\mathrm{i}=1}^{\mathrm{n}}\left[\mathrm{x}_{\mathrm{i}}-\overline{\mathrm{x}}\right]^{2}}}{\overline{\mathrm{x}}}
$$

Where $x_{i}$ is the total number of seeds collected in trap $i$ during the 5 years of study, $\bar{x}$ is the average value of seeds collected in a trap during the study, and $n$ is the total number of traps per species (58 in P. pinea, 15 in P. sylvestris). Low values of CV indicate uniformity in the seed shadow, while large values suggest a clustered distribution of seeds.

- Theoretical distribution of seed arrival:

The empirical distribution of seed arrival to traps was compared with theoretical distributions, as the uniform (defining an even seed shadow), the normal and the negative binomial (clustered seed shadow), by using a Chi-square test. Furthermore, the cumulative curve of collected seeds as a function of the relative distance from the nearest tree (measured in crown radii) was also drawn to detect patterns of seed clustering under the crowns.

- Seed limitation indices:

Clark et al. (1998) and Muller-Landau et al. (2002) proposed two indices to assess whether recruitment is seed-limited by either seed arrival or seed production: seed arrival limitation, defined as the proportion of microsites not receiving seeds; and source limitation, the expected proportion of microsites where seeds are not arriving, considering a uniform distribution of seed arrival. Being $n$ the total number of traps, $a$ the total number of traps receiving at least one seed during the analysed period, and $s$ the total number of seeds collected:

$$
\begin{aligned}
& \text { Seed arrival limitation }=1-\frac{a}{n} \\
& \text { Source limitation }=\exp (-s / n)
\end{aligned}
$$




\section{Annual pattern of seedling emergence and seed success}

In order to check the annual pattern of seedling emergence and seed success we computed the interannual coefficient of variation in the number of emerged seedlings per $\mathrm{m}^{2}$ for each survey subplot [Eq. 1], carrying comparisons between species and sites by a non-parametric Kruskal-Wallis test. Seed success was then computed for each year, sites and species, and correlations between seed dispersal and seed success were carried to determine whether the annual pattern on seedling emergence mimics the annual pattern of seed dispersal.

\section{Spatial pattern of seedling emergence}

The spatial distribution of emerged seedlings was evaluated using the same approach as in the analysis of the spatial distribution of seed dispersal: CV between $1 \mathrm{~m}^{2}$ quadrats (and between species and sites evaluation of differences using Kruskal-Wallis test), theoretical distribution for the observed frequencies (Chi-square test), and charts of the cumulative frequencies of emerged seedlings with respect to the relative distance to the nearest tree.

\section{Seedling survival}

To contrast this hypothesis postulating higher survival rates in large-seeded species, seedling survival was divided into two traits: 1) survival presence - indicating whether in a $1 \mathrm{~m}^{2}$ quadrat with emerged seedlings, there are still live seedlings remaining after one year - and 2) rate of survival - ratio between the amount of one-year old seedlings and the number of seedlings emerged the year before in a $1 \mathrm{~m}^{2}$ quadrat. Spatial pattern of rate of survival was evaluated by computing between quadrats $\mathrm{CV}$, and differences in the rate of survival as a function of site, species, and distance to the closest tree were evaluated.

\section{Results}

\section{Seed production and masting habit}

The differences in the total amount of seed produced between the large-seeded species $(P$. pinea) and the small-seeded species ( $P$. sylvestris) were 15-20 fold (Table 2 ), defining between species significant differences (Kruskal-Wallis W: 36.8275, pvalue $<0.0001$ ), while no significant differences were detected between $P$. sylvestris sites. Both species showed a pattern of interannual variability in seed production (Table 2 ), with $P$. pinea attaining a 78 fold difference between the largest and smallest seed production years (average interannual CV: 1.602), while in $P$. sylvestris the magnitude of this difference is 16 fold (average interannual CV: 1.051 and 0.663 in plots 1 and6 and 8). The Kruskal-Wallis nonparametric test showed significant differences (W: 25.192; p-value < 0.0001) in the within-trap coefficient of variation CV among species, and in the case of $P$. sylvestris, between sites.

Kendall's coefficient of concordance points to the existence of a significant synchrony, within the same species and site, among seeds reaching the traps (Table 2). Moreover, the traps in P. sylvestris plot 8 (timberline) showed a different pattern of interannual variation to those in plots 1 and 6. 
Table 2. Annual mean values of seed production (standard errors in brackets) and within seed-traps average interannual coefficient of variation $(\mathrm{CV})$ and Kendall's coefficient of concordance among traps $(W)$ for seeds collected each year

\begin{tabular}{|c|c|c|c|c|c|c|c|c|c|c|c|}
\hline & \multicolumn{9}{|c|}{ Seeds/m $/ \mathrm{m}^{2}$} & \multicolumn{2}{|c|}{$\begin{array}{c}\text { Kendall's } \\
\text { coefficient of } \\
\text { concordance }\end{array}$} \\
\hline Species & Site & $\mathbf{n}$ & 2005 & 2006 & 2007 & 2008 & 2009 & Mean & $\mathrm{CV}$ & W & p-value \\
\hline P.pinea & Unique & 58 & $\begin{array}{c}0.34 \\
(0.17) \\
\end{array}$ & $\begin{array}{l}15.24 \\
(4.45) \\
\end{array}$ & $\begin{array}{l}26.90 \\
(5.95) \\
\end{array}$ & $\begin{array}{c}3.52 \\
(0.83) \\
\end{array}$ & $\begin{array}{c}0.90 \\
(0.29) \\
\end{array}$ & $9.38^{2}$ & $1.602^{\circ}$ & 0.507 & $<0.0001$ \\
\hline P. sylvestris & Plots $1 \& 6$ & 10 & $\begin{array}{c}84.80 \\
(10.84)\end{array}$ & $\begin{array}{l}431.00 \\
(27.46)\end{array}$ & $\begin{array}{l}118.53 \\
(24.80)\end{array}$ & $\begin{array}{c}38.46 \\
(16.12)\end{array}$ & - & $168.20^{\circ}$ & $1.050^{\circ}$ & 0.684 & $<0.0001$ \\
\hline & Plot 8 & 5 & $\begin{array}{l}178.00 \\
(24.66)\end{array}$ & $\begin{array}{c}95.00 \\
(12.28)\end{array}$ & $\begin{array}{l}361.28 \\
(11.09)\end{array}$ & $\begin{array}{l}136.28 \\
(7.21)\end{array}$ & - & $192.64^{\circ}$ & $0.663^{c}$ & 0.744 & 0.0015 \\
\hline
\end{tabular}

\section{Seed shadow}

A total of $680 P$. pinea pine nuts were collected in the 58 traps $\left(46.89\right.$ seeds. $\mathrm{m}^{-2}, \mathrm{CV}$ between traps: 1.602) during the study period. For P. sylvestris, 10576 seeds were collected in the fifteen traps (705 seeds. $\mathrm{m}^{-2}, \mathrm{CV}$ between traps: 0.252 , no differences between sites, so trap collection data were jointly analysed). Thus, a larger amount of seed arrival and a more uniform distribution over the soil was shown in $P$. sylvestris. After testing the observed distributions of seed arrival (Figure 2), we could not reject the hypothesis of a uniform distribution of seed arrival for $P$. sylvestris $\left(\chi^{2}: 0.666, \mathrm{p}-\right.$ value 0.7165$)$, while for $P$. pinea, with a large zero inflated tailed distribution, no theoretical distribution significantly matched the observed data (closest fit was the negative binomial distribution, $\chi^{2}: 31.213$, $\mathrm{p}$-value $<0.0001$ ).
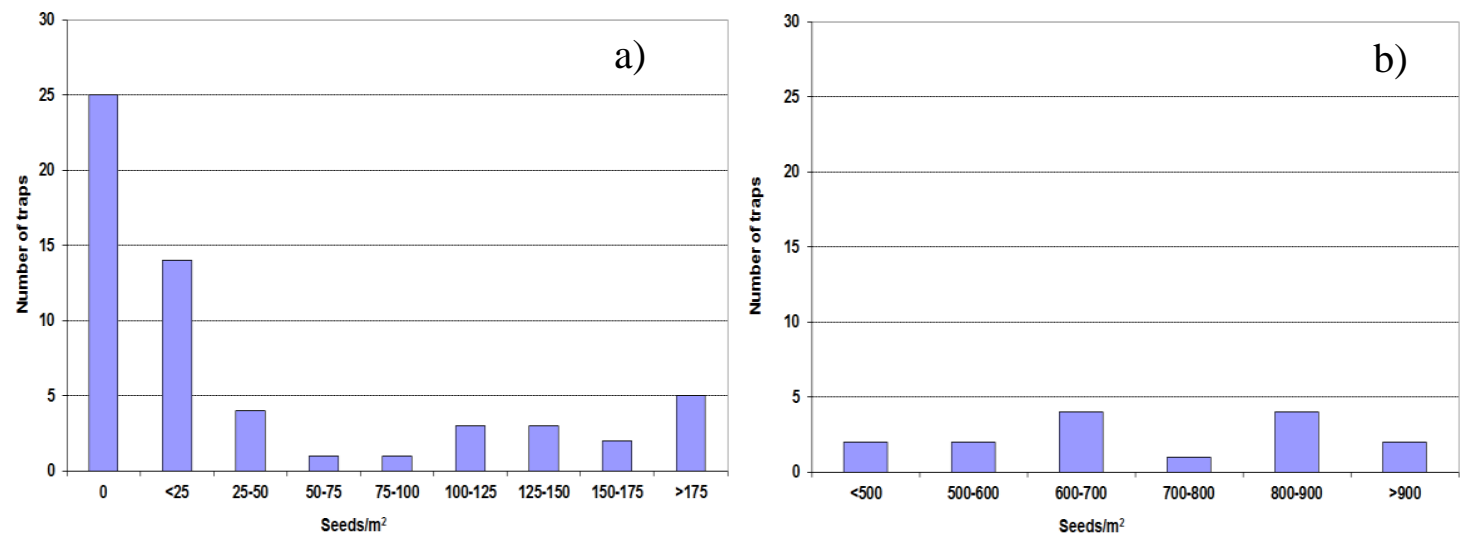

Figure 2. Histogram of frequencies for seed arrival in traps in P. pinea (58 traps, a) and $P$. sylvestris $(15$ traps, $b)$. X axis are adapted to deal with between-species differences in abundance.

These results were confirmed by comparing the cumulative distribution of collected seeds as a function of the relative distance from the nearest tree (Figure 3) for both species. For $P$. pinea more than $75 \%$ of seeds were primarily dispersed beneath the crown, $20 \%$ of the remaining seeds were dispersed up to a distance from the stem of 1.5 times the crown radius, with no seeds at all arriving to those traps located at a distance 
over 2.5 times the crown radius from the nearest stem. On the contrary, for P. sylvestris only $20 \%$ of seeds were released under the crown, while traps beyond three crown radii received almost the same amount of seeds than the traps beneath the crown.
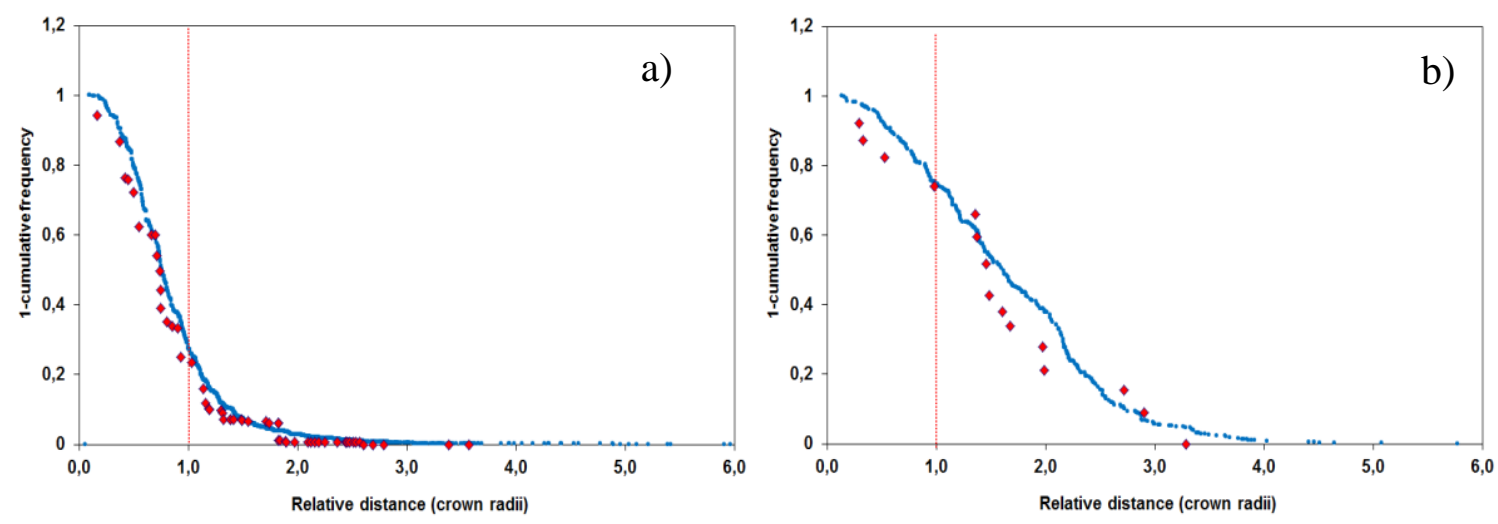

Figure 3. Cumulative frequencies of seed arrival (diamonds) and seedling emergence (dots) for $P$. pinea (a, data from 58 traps and 1080 quadrats) and $P$. sylvestris (b, data from 15 traps and 334 quadrats), as a function of relative distance to the closest tree. Dashed line indicates crown border.

In the case of $P$. pinea 25 out of 58 seed traps received zero seeds within the studied period (Table 3), attaining a global value for seed arrival limitation of 0.431 . A value for the source limitation index of $8.0910^{-6}$ indicated that under a uniform distribution, the number of seeds dispersed during the 5 years period is large enough to arrive to each trap. However, when considering the annual pattern, we observed that in three out of the five studied years (2005, 2008 and 2009), seed limitation was related to seed shortage. For $P$. sylvestris, all the traps received seeds every year, in a sufficient amount that computed values for seed arrival limitation and source limitation indexes were negligible, indicating neither source nor dispersal seed limitations.

Table 3. Seed limitation indexes for Pinus pinea (data from 58 seed traps) and Pinus sylvestris (data from 15 seed traps)

\begin{tabular}{llcccccc}
\hline & Trait & $\mathbf{2 0 0 5}$ & $\mathbf{2 0 0 6}$ & $\mathbf{2 0 0 7}$ & $\mathbf{2 0 0 8}$ & $\mathbf{2 0 0 9}$ & Total \\
\hline \multirow{2}{*}{$\begin{array}{l}\text { P. pinea } \\
\text { 58 seed traps }\end{array}$} & Collected Seeds & 5 & 221 & 390 & 51 & 13 & 680 \\
\cline { 2 - 9 } & Traps with zero seed & 54 & 34 & 31 & 39 & 48 & 25 \\
\cline { 2 - 8 } & Seed arrival limitation* & 0.931 & 0.586 & 0.534 & 0.672 & 0.828 & 0.431 \\
\cline { 2 - 8 } & Source limitation* & 0.917 & 0.022 & 0.001 & 0.415 & 0.799 & $<0.001$ \\
\hline \multirow{2}{*}{\begin{tabular}{l} 
15 sylvestris seed traps \\
\cline { 2 - 8 }
\end{tabular}} & Collected Seeds & 1738 & 4856 & 2917 & 1065 & - & 10576 \\
\cline { 2 - 8 } & Traps with zero seed & 0 & 0 & 0 & 0 & - & 0 \\
\cline { 2 - 8 } & Seed arrival limitation* & 0 & 0 & 0 & 0 & - & 0 \\
\cline { 2 - 8 } & Source limitation* & $<0.001$ & $<0.001$ & $<0.001$ & $<0.001$ & - & $<0.001$ \\
\hline
\end{tabular}

* As defined in equations 3 and 4

\section{Annual pattern of seedling emergence and seed success}

In $P$. pinea, the interannual $\mathrm{CV}$ in seedling emergence (average value 2.054) is significantly larger (W: 183.736 , p-value $<0.0001)$ than in $P$. sylvestris plots 1 and6 
(average value 1.409), and plot 8 (average value 1.583). Significant differences are also detected among plot 1 and 6 vs plot 8 (W: 25.235 , p-value $<0.0001$ ). These results indicate that in $P$. sylvestris emergence is more uniformly distributed among years than in $P$. pinea. However, in all the cases, interannual CV in seedling emergence was larger than the values found for the interannual CV in seed dispersal (Table 4). This means that the annual pattern of seedling emergence is less even than the annual pattern of seed dispersal, suggesting that other factors, rather than only seed availability, drive this process.

Annual seed success (Table 4) does not differ significantly between $P$. pinea and $P$. sylvestris sites (W: 2.195, p-value 0.3336 ). In $P$. pinea stands, the seed success ratio varied between $<0.1 \%$ (2008) and ca. $35 \%$ (2007), with an average value for the studied period of $10.10 \%$. High emergence rates in 2007, followed by low rates in 2008 and 2009 coincided with warm (mean temperature in November 2006: $9.9^{\circ} \mathrm{C}$ ) and cold (mean temperatures in November 2007 and November 2008: $4.0{ }^{\circ} \mathrm{C}$ and $4.5{ }^{\circ} \mathrm{C}$ ) previous fall seasons, the optimal period for seed germination (Manso et al., 2012b). For $P$. sylvestris plots located in productive areas (plots 1 and 6 ) the average seed success is similar to $P$. pinea (12.36 \%), although interannual CV is notably lower. Finally, we observed lower values of seed success $(2.56 \%)$ at the $P$. sylvestris timberline (plot 8). In both $P$. sylvestris sites exceptionally low seed success was detected in 2009 , a year with a very dry spring (only $101 \mathrm{~mm}$ of rainfall, compared with an average spring rainfall of $350 \mathrm{~mm}$ ).

Table 4. Annual pattern of seed arrival, seedling emergence and seed success

\begin{tabular}{|c|c|c|c|c|c|c|c|c|}
\hline Species/site & Trait & 2006 & 2007 & 2008 & 2009 & 2010 & Average & $\mathrm{CV}$ \\
\hline \multirow{4}{*}{ P. pinea } & Seedlings & 37 & 5772 & 8 & 22 & 36 & & - \\
\hline & Seedlings $/ \mathrm{m}^{2}$ & 0.03 & 5.34 & 0.02 & 0.01 & 0.03 & 1.08 & $2.054^{a}$ \\
\hline & Seeds $/ \mathrm{m}^{2}$ & 0.34 & 15.24 & 26.90 & 3.52 & 0.90 & 9.38 & 1.602 \\
\hline & Seed success & $9.94 \%$ & $35.07 \%$ & $0.08 \%$ & $0.21 \%$ & $3.72 \%$ & $10.10 \%$ & 1.453 \\
\hline \multirow{4}{*}{$\begin{array}{c}\text { P. sylvestris } \\
\text { Plots } 1 \text { and } \\
6\end{array}$} & Seedlings & 1914 & 18899 & 4387 & 39 & - & & - \\
\hline & Seedlings/m $\mathbf{m}^{2}$ & 7.70 & 85.18 & 22.45 & 0.63 & - & 28.99 & $1.409^{b}$ \\
\hline & Seeds $/ \mathrm{m}^{2}$ & 84.80 & 431.00 & 118.53 & 38.46 & - & 168.20 & 1.050 \\
\hline & Seed success & $9.08 \%$ & $19.76 \%$ & $18.94 \%$ & $1.64 \%$ & & $12.36 \%$ & 0.694 \\
\hline \multirow{4}{*}{$\begin{array}{l}\text { P. sylvestris } \\
\text { Plot } 8\end{array}$} & Seedlings & 179 & 232 & 2020 & 9 & - & & - \\
\hline & Seedlings/m ${ }^{2}$ & 1.99 & 2.58 & 22.33 & 0.30 & - & 6.80 & $1.548^{c}$ \\
\hline & Seeds $/ \mathrm{m}^{2}$ & 178.00 & 95.00 & 361.28 & 136.28 & - & 192.64 & 0.663 \\
\hline & Seed success & $1.12 \%$ & $2.72 \%$ & $6.18 \%$ & $0.22 \%$ & & $2.56 \%$ & 1.091 \\
\hline
\end{tabular}

Seeds on year $\mathrm{t}$ correspond to seeds dispersed during the previous year t-1; seed success $=$ emerged seedlings / seeds dispersed during the previous year; CV: interannual coefficient of variation. In 2010 , only $P$. pinea trial was measured. In seedlings $/ \mathrm{m}^{2}$ rows, groups with different letter indicate significant differences

In the case of $P$. pinea we found that the year with the largest amount of seed dispersal (2007) was followed by a year with a very low seedling emergence, resulting in a non-significant correlation ( $\mathrm{r}=0.12$, $\mathrm{p}$-value 0.8429$)$ between the amount of seeds dispersed and seed success. Conversely, in the $P$. sylvestris sites a significant positive correlation ( $\mathrm{r}=0.66, \mathrm{p}$-value 0.0198$)$ exists between the amount of seeds dispersed and seed success. 


\section{Spatial pattern of seedling emergence}

During the studied years, we counted 5875 emerged $P$. pinea seedlings (5.44 seedlings per $\mathrm{m}^{2}$ ). The $\mathrm{CV}$ between $1 \mathrm{~m}^{2}$ quadrats in the total amount of emerged $P$. pinea seedlings was 2.430, larger than the CV between seed traps (1.603). However, in $47.77 \%$ of the quadrats (516 of 1080) no seedlings emerged during the analysed period, a value close to that for non-seed traps $(43.10 \%)$. The histogram for the observed frequencies of seedling emergence (Figure 4) showed a quite similar pattern to that obtained for seed dispersal (Figure 2). Tests for theoretical distributions did not provide significant results, although - similar to seed dispersal - the negative binomial was the distribution that best match $\left(\chi^{2}: 1303.380\right.$, p-value<0.0001). Thus, the spatial distribution of seedlings in $P$. pinea closely mimics the spatial pattern of seed dispersal, with most of the emerged seedlings located within the influence area of the crown and an absence of seedlings in the large gaps (Figure 5a). Confirming this, when we compared the cumulative frequencies curves of seed dispersal and seedling emergence (Figure 3) we only detected slight differences at a distance over 2 crown radius from the closest tree, where $3 \%$ of seedlings emerged though only $0.7 \%$ of seeds are dispersed.
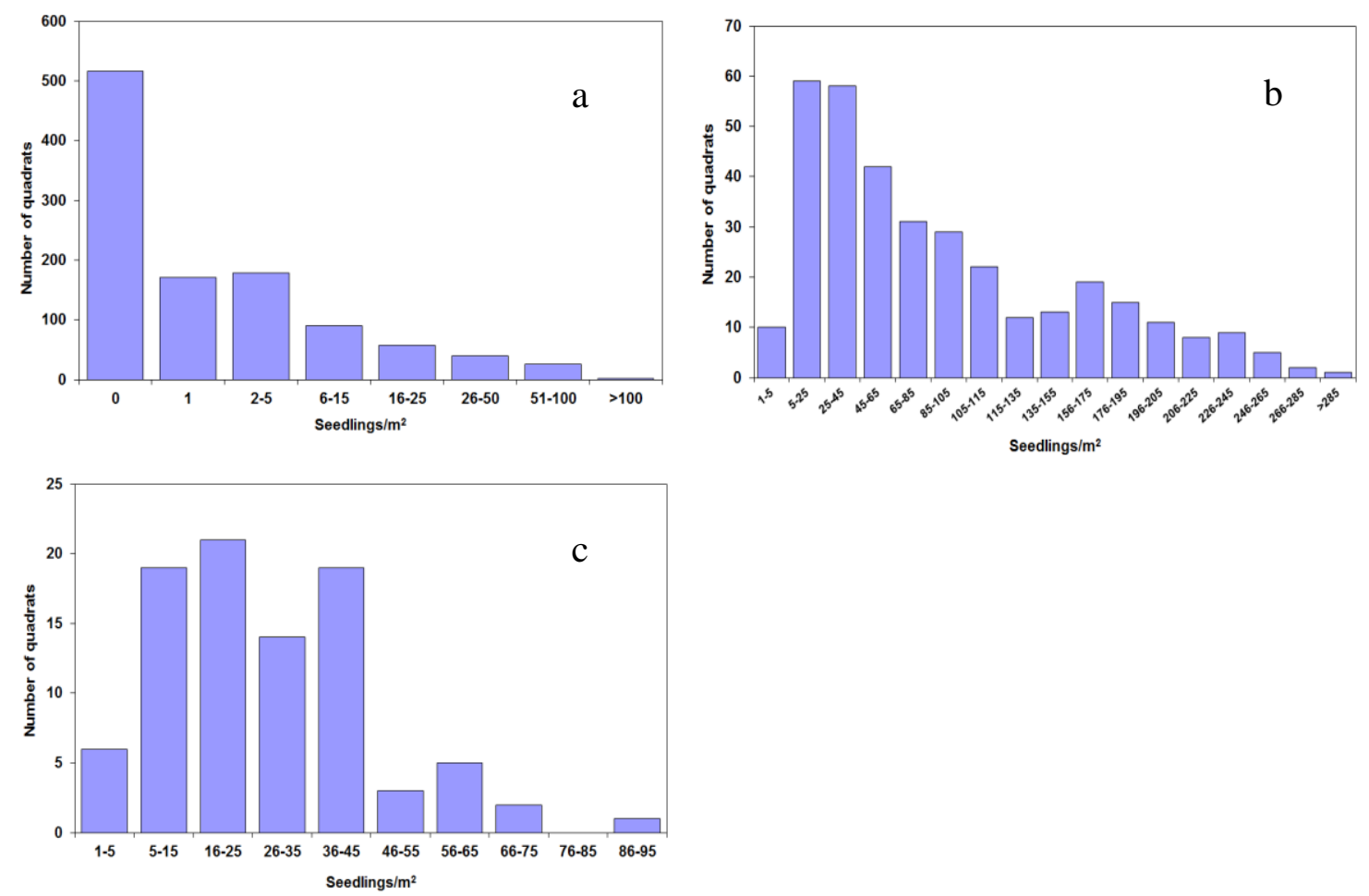

Figure 4. Histogram of frequencies for emerged seedlings in P. pinea (a) and P. sylvestris plots land6 $(b)$ and plot $8(c) . X$ and $Y$ axis are adapted to deal with between-species and betweensites differences in abundance and sampling intensity.

In the case of $P$. sylvestris, significant differences were found between sites in the average value of emergence throughout the study (115.95 and 27.21 seedlings per $\mathrm{m}^{2}$ in plots 1and6 and plot 8; W: 114.410, p.value <0.0001) contrasting with the result obtained for dispersed seeds. All the quadrats showed at least one emerged seedling during the period. At within-site scale, the CV for the total amount of emerged 
seedlings between $1 \mathrm{~m}^{2}$ quadrats was 0.652 and 0.387 for plots 1 and 6 and plot 8 , values notably larger than those obtained for seed dispersal traps (CV: 0.252). Regarding the theoretical distributions (Figure 4), we rejected the hypothesis of uniform distribution $\left(\chi^{2}: 75.721\right.$ and 61.289; $\mathrm{p}$-value $<0.0001$ for plots 1 and6 and 8$)$, although at 0.01 level we could not reject the hypothesis of normal seedling distribution $\left(\chi^{2}=16.128\right.$ and 6.178; p-values 0.0131 and 0.2892). The large differences observed in the cumulative curves of frequencies for seed dispersal and seedling emergence (Figure 3) also confirms these changes in the spatial distribution for $P$. sylvestris, pointing to a less uniform distribution of emerged seedling, suggesting that seed success can be influenced by crown cover (Figure 5b).

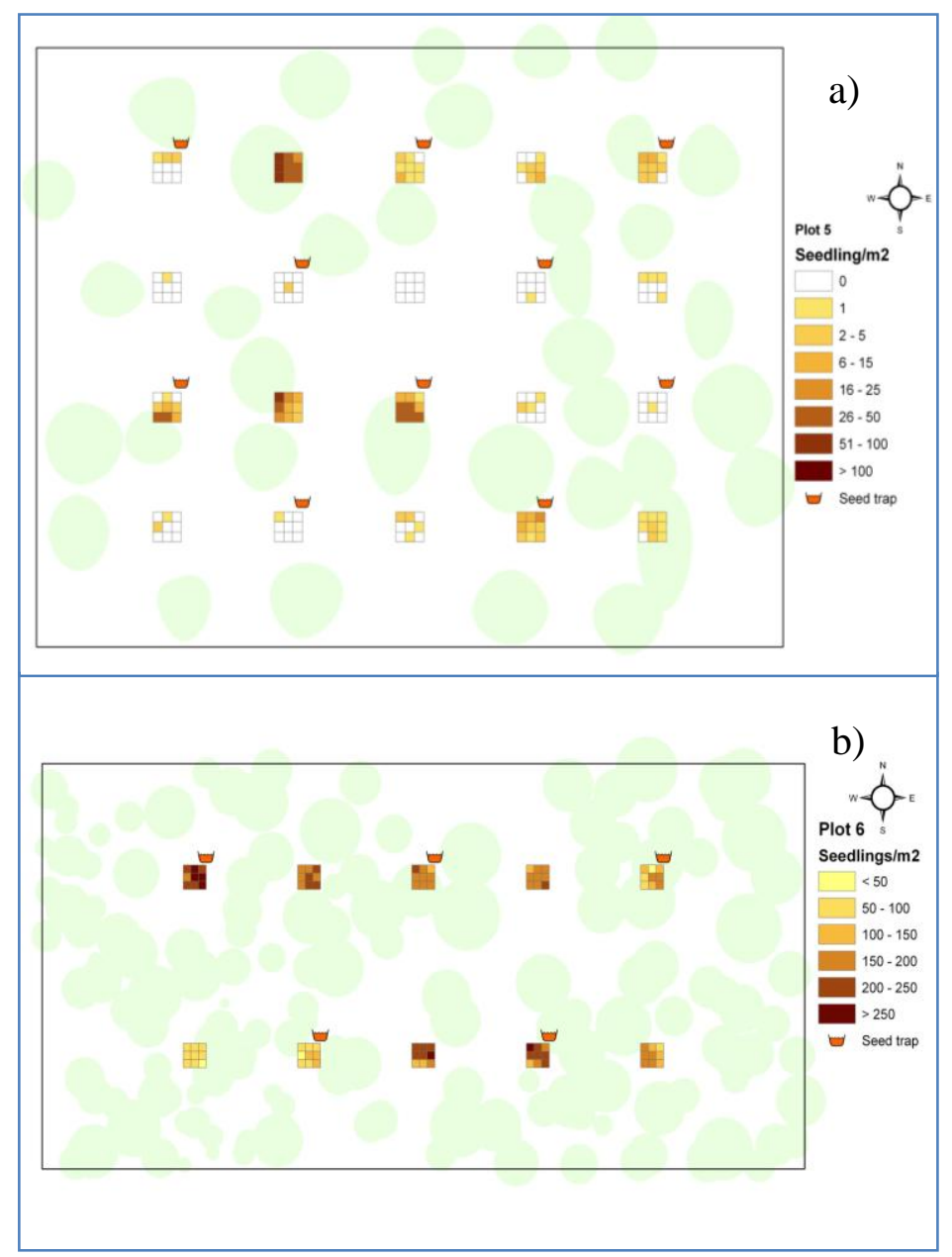

Figure 5. Crown covertures, subplot location and seedling emergence in P. pinea plot 5 (a) and $P$. sylvestris plot $6(b)$

\section{Seedling survival}

One-year old seedling survival in $P$. pinea was only detected in $25 \%$ of the $1 \mathrm{~m}^{2}$ quadrats where seedlings had emerged the previous year, while in $P$. sylvestris survival presence reached values of $89 \%$ in plots 1 and 6 and $46 \%$ in plot 8 .

The mean first year survival rate for $P$. pinea was 0.091 , while for $P$. sylvestris the survival rate was significantly larger $(0.199$ and 0.242 for plot 1 and 6 and plot 8 , 
respectively, W: 220.160, p-value <0.0001). The CV defining spatial variation of survival rate was larger in $P$. pinea (2.4289) than in $P$. sylvestris $(0.8111$ and 1.4786 in plots 1and6 and plot 8), indicating greater uniformity in seedling survival in $P$. sylvestris. Finally, significantly lower rates of survival were detected for $P$. pinea in those quadrats located beyond 1.5 crown radii from the closest tree (W: 17.205 , p-value: 0.0041), while in P. sylvestris significant difference (W: 25.194, p-value: 0.0007) were found at positions beyond three crown radii (Figure 6 ).
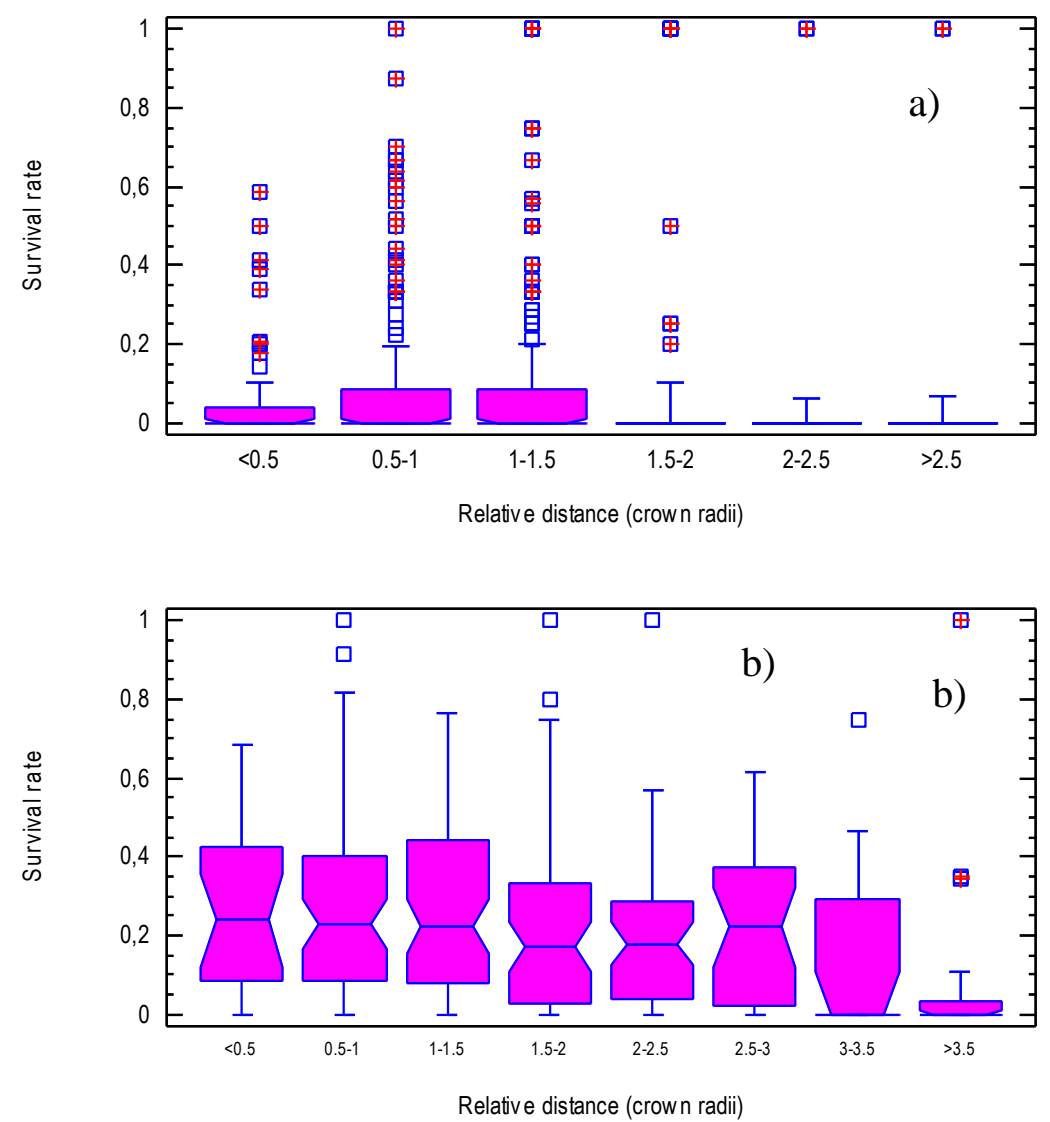

Figure 6. Rate of seedling survival in P. pinea (a) and P. sylvestris (b) as a function of relative distance to the closest tree classes, measured in crown radii.

\section{Discussion}

Our results do not entirely support our main hypotheses since some of the evolutionary advantages for large-seeded species based on the classical trade-off theory postulated by Smith and Fretwell (1974) were not shown by P. pinea (Table 5), especially those assumptions regarding the interannual pattern of seedling emergence, seed success and seedling survival.

We can support the secondary hypothesis that large-seeded species produce a smaller amount of seeds. The differences of 15-20 fold in the number of seeds produced between the two studied species, in contrast with the 60 fold difference in seed weight, suggests that $P$. pinea allocates more resources to seed production (Cabanettes and Rapp, 1981). Both species showed significant interannual variability 
and synchrony in seed production between trees within the same site. $P$. pinea shows larger interannual variability and several years with almost no production, while $P$. sylvestris shows smaller interannual differences and an absence of null crops, as reported by Hilli et al. (2008). It has been suggested that masting habit, synchrony and the existence of years with almost null crops (e.g. 2005 or 2009) in large-seeded species are evolutionary mechanisms to tackle predators and favour animal dispersal by scatter-hoarders (Janzen, 1971; Kelly, 1994; Vander Wall, 2002). However, the two consecutive mast years (2006 and 2007) found for $P$. pinea appear to contradict the classic satiation-starvation theory, revealing the important role played by climatic variables in the masting response. Evidences that masting habit in $P$. pinea is highly influenced by rain events during the year prior to flowering, coinciding with bud formation, have previously been widely reported (Mutke et al., 2005; Calama et al,. 2011). In P. sylvestris the absence of null crops guarantees a constant supply of seeds, a trait expected in small-seeded species.

In our study, the hypothesis of seed size as the main trait defining interspecific differences on the shape of the seed shadow (Willson, 1993; Khurana et al., 2006) can be confirmed. Seed arrival to the ground is severely limited in $P$. pinea since most of the seeds are dispersed and clumped under or close to the crown of parent trees (Barbeito et al., 2008), being a major cause of seedling recruitment failure in $P$. pinea (Manso et al., 2012a). The lack of seed also seems to be a problem for the regeneration of $P$. pinea stands in non-mast years, when more than $80 \%$ of the sites do not receive seeds. However, when considering a period of five years, the amount of seeds arriving to the ground is enough to regenerate the stand. Conversely, P. sylvestris seeds are uniformly dispersed and distributed throughout the territory, even in timberline stands and years with low seed production.

Table 5. Expected and observed regeneration traits according to classical secondary hypotheses on seed ecology; $(\sqrt{ })$ indicates match, while $(X)$ means divergence

\begin{tabular}{|c|c|c|c|c|}
\hline & \multicolumn{2}{|l|}{ Pinus pinea } & \multicolumn{2}{|l|}{ Pinus sylvestris } \\
\hline Trait & Expected secondary hypotheses & Obs & Expected secondary hypotheses & Obs \\
\hline $\begin{array}{l}\text { Seed production } \\
\text { and masting habit }\end{array}$ & $\begin{array}{c}\text { Smaller amount of seed } \\
\text { Large interannual variability } \\
\text { Years showing seed source } \\
\text { limitations }\end{array}$ & $\begin{array}{l}\sqrt{ } \\
\sqrt{ } \\
\sqrt{ }\end{array}$ & $\begin{array}{c}\text { Large amount of seed } \\
\text { Low interannual variability } \\
\text { Enough amount of seed every } \\
\text { year }\end{array}$ & $\begin{array}{l}\sqrt{ } \\
\sqrt{ } \\
\sqrt{ }\end{array}$ \\
\hline Seed shadow & $\begin{array}{c}\text { Uneven } \\
\text { Seeds clustered under crowns } \\
\text { Seed anival limitations }\end{array}$ & $\begin{array}{l}\sqrt{ } \\
\sqrt{ } \\
\sqrt{ }\end{array}$ & $\begin{array}{c}\text { Uniform } \\
\text { No seed limitations }\end{array}$ & $\begin{array}{l}\sqrt{ } \\
\sqrt{ }\end{array}$ \\
\hline $\begin{array}{l}\text { Annual pattern of } \\
\text { seed emergence } \\
\text { and seed success }\end{array}$ & $\begin{array}{c}\text { Mimicking annual pattem of } \\
\text { previous year seed dispersal } \\
\text { Large seed success } \\
\end{array}$ & $\begin{array}{l}\mathrm{X} \\
\mathrm{X}\end{array}$ & $\begin{array}{c}\text { Not mimicking annual pattem of } \\
\text { previous year seed dispersal } \\
\text { Low seed success }\end{array}$ & $\begin{array}{l}\sqrt{ } \\
\sqrt{ } \\
\end{array}$ \\
\hline $\begin{array}{l}\text { Spatial pattern of } \\
\text { seedling } \\
\text { emergence }\end{array}$ & Similar to seed shadow & $\sqrt{ }$ & $\begin{array}{l}\text { Unlike seed shadow } \\
\text { Microsite differences }\end{array}$ & $\begin{array}{l}\sqrt{ } \\
\sqrt{ }\end{array}$ \\
\hline Seedling survival & $\begin{array}{c}\text { Large } \\
\text { Broad range of adequate } \\
\text { conditions } \\
\end{array}$ & $\begin{array}{l}\mathrm{X} \\
\mathrm{X}\end{array}$ & $\begin{array}{c}\text { Low } \\
\text { Narrow range of adequate } \\
\text { conditions } \\
\end{array}$ & $\begin{array}{l}\sqrt{ } \\
\sqrt{ }\end{array}$ \\
\hline
\end{tabular}

On the contrary, our results do not support the proposed hypothesis that seed size controls the annual pattern of emergence and seed success. Although postulated by the reserve trade-off theory (Smith and Fretwell, 1974; Moles et al., 2005), we did not find 
higher seed success in $P$. pinea. Moreover, higher emergence rates in mast years were found in the case of the small-seeded species, but not in the large-seeded one (contradicting again the satiation-starvation theory). A major climatic control over this trait was observed in $P$. pinea, associated with favourable warm conditions during fall season. Furthermore, the low rate of emergence in 2008 occurred after two very good crops in 2006 and 2007, indicating substantial impact of winter predation, when rodents are more active in Mediterranean environments (Diaz et al., 2010). The combined effect of unfavourable climatic conditions and predators could reduce seedling recruitment almost to zero, even in mast years, defining a clear bottleneck for $P$. pinea regeneration (Manso et al., 2012b). In $P$. sylvestris, plots 1 and6 showed constant rates of emergence except for the very dry spring of 2009, while in plot 8 we identified the lowest rates of emergence throughout the study. This indicates an environmental control at the timberline that limits seed survival and germination, partly related to water availability in summer (Barbeito et al., 2009). Even though predation pressure is higher in the case of species with large seeds, the possible effect of foraging rodents and ants on $P$. sylvestris seed survival should be considered, as it can severely reduce the total amount of seed available (Castro et al., 1999).

The $P$. pinea seedling shadow largely mimics the seed primary dispersal shadow, which is in accordance with the trade-off hypothesis. However, since the role of animal dispersers is not taken into account by seed traps, we compared the cumulative curves for $P$. pinea seed arrival and seedling emergence, which revealed a greater right tail in seedling distribution. Nevertheless, the role of secondary dispersal in the species is less important than might be expected, with only $3 \%$ of seedlings appearing at a distance of twice the crown radius from the stems. In P. sylvestris stands, the spatial pattern of seedling distribution is much more uneven than the pattern of seed arrival to the soil, which also agrees with our expected hypothesis. While seeds cover the territory uniformly, the emergence of seedlings follows a close to normal distribution, indicating that some sites are more favourable than others for emergence and establishment, and confirming the dependence between seed size and safe sites (Lusk and Kelly, 2003). This pattern of dependence has also been observed in other wind dispersed seed species, such as Abies alba Mill. (Sagnard et al., 2007) or Pinus nigra (Lucas-Borja et al., 2012), and it agrees with the previous results for the species that identify medium light conditions as being more favourable for seedling emergence and growth (Pardos et al., 2007, 2008; Barbeito et al., 2009, 2011).

Finally, once more our results do not confirm the trade-off hypothesis (Smith and Fretwell, 1974; Willson, 1993) of a positive correlation between seed size and seedling survival, since higher rates of survival were shown by the small-seeded species $(P$. sylvestris). Classical theories also postulate that large seeds tend to reach sites that are more favourable for emergence and survival. In our study this pattern did not occur, since $P$. pinea seedlings only survived in $25 \%$ of the sites where emergence occurred, while in the case of $P$. sylvestris, survival presence reached values of up to $85 \%-95 \%$. However, in both species the spatial pattern of survival mimics the pattern of seedling emergence, since $P$. pinea seedlings tend to show higher survival rates under the crown, while $P$. sylvestris attains lower survival values in very exposed areas at the timberline and higher survival rates for plants in medium exposed positions located in mid-altitude areas. Hence, the main factors governing emergence also have an important impact on survival for both species. 


\section{Conclusions}

Our study confirms that for the analysed species and sites the main inter-specific differences in the total amount of produced seed, masting habit, and spatial patterns of seed arrival and seedling emergence can be explained on the basis of the differences in seed size and trade-off theory by Smith and Fretwell (1974). On the contrary, the expected evolutionary advantages of higher rates of emergence, seed success and seedling survival in the large-seeded $P$. pinea are not shown. In $P$. pinea severe limitations are identified not only in terms of seed arrival and seed source in non-mast years (as expected in a large-seeded species), but also in emergence and seedling survival, limiting regeneration success to very narrow conditions. In P. sylvestris limitations were uniquely found in timberline areas, preventing seed germination and subsequent seedling emergence. These results support the hypothesis that in resourcelimited environments climatic conditions govern inter-annual patterns in regeneration and the evolutionary reproductive advantages related to species seed size are probably minimized. However, given the shortages of the study, uniquely focusing on two species growing on their most representative areas and based on nonhomogeneous experimental trials, these conclusions should be cautiously considered. Future research effort should point to evaluate these hypotheses over a wider range of Mediterranean pine species and sites.

Acknowledgements. Present study has been carried under the technical context and financial support of the projects CPE-03-001-C5.2, AGL2007-65795-CO2-02, RTA-2007-00044-00-00, AGL2010-15521 and RTA2013-011-C02.1

\section{REFERENCES}

[1] Aizen, M.A. , Patterson, W.A. (1990): Acorn size and geographical range in the North American oaks (Quercus L.) - Journal of Biogeography 17: 327-332

[2] Aizen, M.A., Woodcock, H. (1992): Latitudinal trends in acorn size in eastern North American species of Quercus - Can J Bot 70: 1218-1222

[3] Baker, H.G. (1972): Seed weight in relation to environmental conditions in California Ecology 53: 997-1010

[4] Barbeito, I., Pardos, M., Calama, R., Cañellas, I. (2008): Effect of stand structure on stone pine (Pinus pinea L.) regeneration dynamics - Forestry 81(5): 617-629

[5] Barbeito, I., Fortin, M.J., Montes, F. , Cañellas, I. (2009): Response of pine natural regeneration to small-scale spatial variation in a managed Mediterranean mountain forest -Appl Veg Sci 12: 488-503

[6] Barbeito, I., Le May, V., Calama, R. , Cañellas, I. (2011) :Regeneration of Mediterranean Pinus sylvestris under two alternative shelterwood systems within a multiscale framework - Can J For Res 41: 341-351

[7] Cabanettes, A., Rapp, M. (1981): Biomasse, minéralomasse et productivité d'un écosysteme à Pins pignons (Pinus pinea L.) du littoral méditerranéen. III.- Croissance Acta Oecologica 2: 121-136

[8] Calama, R. , Montero, G. (2007): Cone and seed production from stone pine (Pinus pinea L.) stands in Central Range (Spain) - Eur J For Res 126 (1): 23-35

[9] Calama, R., Tomé, J., Gordo, J., Mutke, S., Montero, G. , Tomé, M. (2011): Modelling spatial and temporal variability in a zero-inflated variable: the case of stone pine (Pinus pinea L.) cone production - Ecol Model 222: 606-618 
[10] Castro, J., Gómez ,J.M., García, D., Zamora, R. , Hódar, J.A. (1999): Seed predation and dispersal in relict Scots pine forests in Southern Spain - Plant Ecology 145: 115-123

[11] Clark, J.S., Macklin, E. , Wood, L. (1998): Stages and spatial scales of recruitment limitation in Southern Appalachian Forests - Ecol Monogr 68: 213-235

[12] Díaz, M., Torre, I. , Arrizabalaga, A. (2010): Relative roles of density and rainfall on the short-term regulation of Mediterranean wood mouse (Apodemus sylvaticus) populations - Acta Theriologica 55: 251-260

[13] Foster, S.A. (1986): On the adaptative value of large seeds for Tropical Moist Forest trees: a review and synthesis - The Botanical Review 52 (3): 260-299

[14] Gross, K.L. (1984): Effects of seed size and growth form on seedling establishment of six monocarpic perennial plants - Journal of Ecology 72: 369-387

[15] Grotkopp, E., Rejmánek, M. , Rost ,T.L. (2002): Toward a causal explanation of plant invasiveness: seedling growth and life-history of 29 pine species - Am Nat 159 (4): 396419

[16] Guo, Q.F., Brown, J.H., Valone, T.J. , Kachman, S.D. (2000) :Constraints of seed size on plant distribution and abundance - Ecology 81(8): 2149-2155

[17] Harper, J.L. , Obeid, M. (1967): Influence of seed size and depth of sowing on the establishment and growth of varieties of fibre and oil seed flax - Crop Sci 7: 527-532

[18] Harper, J.L., Lovell, P.H. , Moore, K.G. (1970): The shape and sizes of seeds - Ann Rev Ecol Syst 1: 327-356

[19] Hilli, A., Hokkanen, T. , Hyvonen, J. (2008): Long-term variation in Scots pine seed crop size and quality in northern Fin - Scand J For Res 23 (5),:395-403

[20] Jackson, J.F. (1981) :Seed size as a correlate of Temporal and Spatial patterns of seed fall in a Neotropical fores - Biotropica 13 (2): 121-130

[21] Janzen, D.H. (1971): Seed predation by animals - Ann Rev Ecol Syst 2: 465-492

[22] Kelly, D. (1994): The evolutionary ecology of mast seeding - TREE 9: 465-470

[23] Khurana E., Sagar R. , Singh J.S. (2006) Seed size: a key trait determining species distribution and diversity of dry tropical forest in northern India - Acta Oecologica 29: 196-204

[24] Kimmins, J.P. (2002): Forest Ecology, 3rd edition - Prentice Hall. New Jersey.

[25] Lanner, R.M. (1998): Seed dispersal in Pinus. In. Richardson D.M. (ed.) Ecology and Biogeography of Pinus - Cambridge Univesity Press. Cambridge, pp. 281-295

[26] Legendre, P. (2005): Species association: the Kendall Coefficient of Concordance revisited - Journal of Agricultural, Biological and Environmental Statistics 10(2): 226245

[27] Long, T.J. , Jones, R.H. (1996): Seedling growth strategies and seed size effects in fourteen oak species native to different soil moisture habitats -Trees 11: 1-8

[28] Lucas-Borja, M.E., Fidalgo, T., Lousada, J.L., Silva-Santos, P., Martínez, E.. , AndrésAbellán, M. (2012): Natural regeneration of Spanish black pine [Pinus nigra Arn. ssp. salzmannii (Dunal) Franco] at contrasting altitudes in a Mediterranean mountain area Ecol Res DOI 10.1007/s11284-012-0969-x

[29] Lusk, C.H. , Kelly, C.K. (2003): Interspecific variation in seed size and safe sites in a temperate rain forest - New Phytol 158: 535-541

[30] Manso, R., Pardos, M., Keyes, C. , Calama, R. (2012a): Modelling the spatio-temporal pattern of primary dispersal in stone pine (Pinus pinea L.) stands in the Northern Plateau (Spain) - Ecol Model 226: 11-21

[31] Manso, R., Fortin, M., Calama, R., Pardos, M. (2012b) :Modelling seed germination in forest tree species through survival analysis. The Pinus pinea L. case study - For Eco Manage 289: 515-524

[32] Moles, A.T., Westoby, M. (2004): What do seedlings die from and what are the implications for evolution of seed size? - Oikos 106(1): 193-199

[33] Moles, A.T. , Westoby, M. (2006): Seed size and plant strategy across the whole life cycle - Oikos 113: 91-195 
[34] Moles, A., Ackerly, D.D., Webb, C.O., Tweddle, J.C., Dickie, J.B. , Westoby, M. (2005): A brief history of seed size - Science 307: 576-580

[35] Montero, G., Serrada, R. , Reque, J. (2008): Compendio de Selvicultura de Especies. INIA - Fundación Conde del Valle de Salazar. Madrid

[36] Muller-Landau, H.C., Wright, S.J., Calderón, O., Hubbell, S.P. , Foster, R.B. (2002): Assessing recruitment limitation: concepts, methods and case-studies from a Tropical Forest. - In: Levey, D.J., Silv,a W.R. , Galetti, M. (eds.) Seed dispersal and frugivory: Ecology, Evolution and Conservation - CAB International. Wallingford, pp 35-53

[37] Muller-Landau, H.C. (2010): The tolerance-fecundity trade-off and the maintenance of diversity in seed size - PNAS 107 (9): 4242-4247

[38] Mutke, S., Gordo, F.J. , Gil, L. (2005): Variability of Mediterranean Stone pine cone production: yield loss as response to climatic change - Agric For Met 132: 263-272.

[39] Pardos, M., Ruiz del Castillo, J., Cañellas, I. , Montero, G. (2005): Ecophisiology of natural regeneration of forest stands in Spain - Invest Agr Sist Recur For 14 (3): 434-445

[40] Pardos, M., Montes, F., Aranda, I. , Cañellas, I. (2007): Influence of environmental conditions on Scots pine (Pinus sylvestris L.) germinant survival and diversity in Central Spain - Eur J For Res 126(1): 37-47

[41] Pardos, M., Montes, F. , Cañellas, I. (2008): Spatial dynamics of natural regeneration in two differently managed Pinus sylvestris stands before and after silvicultural intervention using replicated spatial point patterns - For Sci 54(3): 260-272

[42] Robledo-Arnuncio, J.J., Collada, C., Alía, R. , Gil, L. (2005): Genetic structure of montane isolates of Pinus sylvestris L. in a Mediterranean refugial area - Journal of Biogeography 32: 595-605

[43] Ruiz de la Torre, J. , Ceballos, L. (1979) :Árboles y Arbustos de la España Peninsular ETS Ingenieros de Montes. Madrid

[44] Sagnard, F., Pichot, C., Dreyfus, P., Jordano, P. , Fady, B. (2007): Modelling seed dispersal to predict seedling recruitment: recolonization dynamics in a plantation forest Ecol Model 203: 464-474.

[45] Smith, C.C. , Fretwell, S.D. (1974): The optimal balance between size and number of offspring - Am Nat 108: 499-506

[46] Smythe, N. (1970): Relationship between fruiting seasons and seed dispersal methods in a Neotropical forest - Am Nat 104: 25-35

[47] Vander Wall, S.B. (2002): Masting in animal-dispersed pines facilitates seed dispersal Ecology 83(12): 3508-3516.

[48] Westoby, M., Jurado, E. , Leishman, M. (1992): Comparative evolutionary ecology of seed size - Trees 7 (11): 368 - 372.

[49] Willson, M.F. (1993): Dispersal mode, seed shadows and colonization patterns Vegetatio 107/108: 261-280 